\title{
Effect of electrolyzed reduced water on malondialdehyde levels and neutrophil cells in aggressive periodontitis
}

\author{
Markus B Rahardjo', Rini D Ridwan ${ }^{1 *}$, Delaneira AD Hikmah ${ }^{2}$ \\ ${ }^{1}$ Department of Oral Biology, Faculty of Dental Medicine, Universitas Airlangga, Surabaya, Indonesia, ${ }^{2}$ Undergraduate Student, \\ Faculty of Dental Medicine, Universitas Airlangga, Surabaya, Indonesia
}

*For correspondence: Email: rini-d-r@fkg.unair.ac.id; Tel: (+62 31) 5030255, 5020256

\begin{abstract}
Purpose: To evaluate the effects of electrolyzed reduced water (ERW) on malondialdehyde (MDA) levels and neutrophil cells in Wistar rats suffering from aggressive periodontitis.

Methods: Wistar rats (Rattus norvegicus) were infected with A. actinomycetemcomitans before being divided into a control group and a treatment group. The control group was treated orally with distilled water ( $\mathrm{pH}$ 7.0), while the treatment group was administered with ERW ( $\mathrm{pH} 9.8,20 \mathrm{ml} /$ day) for three successive days. Gingival tissue taken post-treatment was examined to determine the number of neutrophils and MDA level. Hematoxylin eosin staining was performed to identify neutrophil cells while MDA levels were determined by colorimetric assay.

Results: The number of neutrophils in the control group (30.04 \pm 15.30$)$ was higher than that of the treatment group (7.76 \pm 2.52 ), while the MDA levels of the control and treatment groups were $4.58 \pm$ 0.66 and $4.30 \pm 0.81$, respectively $(p<0.05)$.

Conclusion: ERW demonstrates the ability to reduce neutrophil cells without altering MDA levels in Wistar rats suffering from aggressive periodontitis. This is an indication that ERW was an effective material to manage aggressive periodontitis.
\end{abstract}

Keywords: Periodontitis, Electrolyzed reduced water, Malondialdehyde, Neutrophil cells

\begin{abstract}
This is an Open Access article that uses a funding model which does not charge readers or their institutions for access and distributed under the terms of the Creative Commons Attribution License (http://creativecommons.org/licenses/by/4.0) and the Budapest Open Access Initiative (http://www.budapestopenaccessinitiative.org/read), which permit unrestricted use, distribution, and reproduction in any medium, provided the original work is properly credited.
\end{abstract}

Tropical Journal of Pharmaceutical Research is indexed by Science Citation Index (SciSearch), Scopus, International Pharmaceutical Abstract, Chemical Abstracts, Embase, Index Copernicus, EBSCO, African Index Medicus, JournalSeek, Journal Citation Reports/Science Edition, Directory of Open Access Journals (DOAJ), African Journal Online, Bioline International, Open-J-Gate and Pharmacy Abstracts

\section{INTRODUCTION}

Periodontitis is an inflammatory disease resulting in the destruction of tissues and structures surrounding the teeth and represents a major worldwide oral disease [1]. Data issued by the Health Research and Development Department of the Indonesian Ministry of Health (Riskesdas) in 2014 confirmed that the prevalence of periodontitis within the country remained high [2], constituting the second most prevalent oral disease after caries [3].

Aggressive periodontitis is a destructive inflammatory disease characterized by periodontal attachment loss and bone resorption [4]. Patients with this condition often demonstrate an inadequate immune response to pathogenic organisms. Periodontal pathogens will induce a significantly elevated production of inflammatory mediators [5]. Aggressive periodontitis is 
predominantly caused by the gram-negative bacteria, $A$. actinomycetemcomitans one virulent factor of which is leukotoxin, an inflammatory mediator activating inflammatory cells, such as leukocytes, polymorphonuclear (PMN), and macrophages $[6,7]$.

The superoxide of reactive oxygen species (ROS) is produced by inflammatory cells as a defense mechanism response to infection. An increased level of ROS can be destructive to the body since it has the same properties as interleukin which damages tissue if produced in excessive amount. High levels of ROS can lead to lipid peroxidation a secondary product of which is malondialdehyde (MDA), a biomarker of ROS activities [8,9]. Excessive ROS must be eliminated in order to avoid tissue damage. It can be reduced by a component such as active hydrogen which is able to bind to the free electrons of ROS. In addition, active hydrogen atoms can inhibit the expressions of proinflammatory cytokine [10].

Electrolyzed reduced water (ERW) is also known as alkaline electrolyzed water, alkali-ionic water, alkaline cathodic water and alkaline ionized water. ERW can be defined as water with an alkaline $\mathrm{pH}$ which contains hydrogen-rich molecules [11]. Active hydrogen atoms can be obtained from ERW at the cathode by means of an electrolysis process.

ERW contains low levels of dissolved oxygen and high levels of dissolved hydrogen, while demonstrating a negative redox potential. ERW at a $\mathrm{pH}$ of 9.8 has been reported to reduce levels of ROS in the blood plasma of patients with kidney disorders [12]. Previous studies have also confirmed active hydrogen atoms as demonstrating the ability to decrease the activities of ROS [11,12].

ERW is produced through a process of electrolysis or ionization. The result of water electrolysis is either acid or base form. Acidic water, while unsuitable for human consumption is appropriate for the treatment of the human body and maintaining levels of hygiene. Meanwhile, ERW or alkaline water has certain health benefits when consumed [13]. The aim of this study is to evaluate the effects of ERW on MDA levels and neutrophil cells in Wistar rats suffering from aggressive periodontitis.

\section{EXPERIMENTAL}

\section{Animals}

This study consisted of laboratory-based experi- mental research involving the use of rats (Rattus norvegicus) as animal subjects. The inclusion criteria included the following; male, aged 2-5 months, in healthy condition and weighing between 150 and $250 \mathrm{~g}$. Research subjects were given seven days to acclimatize. Ethical permission for the study was obtained in accordance with the guidelines of the Board for Animal Experiments at the Faculty of Dental Medicine, Universitas Airlangga (no. 176/KKEPK.FKG/VIII/2016) which followed the Guidelines on the Care and Use of Animals for Scientific Purposes [14].

\section{Induction of aggressive periodontitis}

The research subjects were divided into two groups: control and treatment $(n=7)$, both of which were induced with $A$. actinomycetemcomitans bacteria $0.5 \mathrm{~mL}$ at a dose of $10^{8} \mathrm{CFU} / \mathrm{mL}$ once a day for five days or until their mandibular right and left first molar regions were inflamed.

\section{Experimental design}

The animals in the control group were treated orally with distilled water of neutral $\mathrm{pH}(\mathrm{pH} 7.0)$ at a dose of $20 \mathrm{~mL}$ per day $(5 \mathrm{~mL} \times 4)$ for three days. In contrast, those constituting the treatment group were orally treated with $\mathrm{ERW}$ with a $\mathrm{pH}$ of 9.8 at a dose of $20 \mathrm{~mL}$ per day $(5 \mathrm{~mL} \times 4)$ over the same period.

\section{Histological staining}

After three days of ERW supplementation, the experiment animals were sacrificed by injecting a $50 \mathrm{mg} / \mathrm{kg}$ dose of ketamine (Combipar, Jakarta, Indonesia). The gingival tissues were extracted and fixed with buffered formalin solution (P4417, Sigma, Indonesia) for 24 hours before being dehydrated and cleared with alcohol. Samples were then embedded in paraffin prior to $\mathrm{HE}$ staining. Neutrophil cell identification was performed by means of a light microscope at 1000x magnification.

\section{Determination of MDA levels}

$300 \mathrm{mg}$ of gingival tissues were pulverized and homogenized using $1 \mathrm{~mL}$ of cold phosphate buffer, (P4417, Sigma, Indonesia) and $10 \mu \mathrm{L}$ of probucol solution. Samples of $200 \mu \mathrm{L}$ were placed in assay tubes, and R1 reagents of MDA kit (MDA-586 Bioxytech, OXIS Health Products, Portland, USA) were added. The samples were vortexed and $150 \mu \mathrm{L}$ of $\mathrm{R} 2$ reagents were added to each tube. All control and treatment group assay tubes were incubated at a temperature of 
$45{ }^{\circ} \mathrm{C}$ for 60 minutes. The samples were subsequently centrifuged (DSC-200A Dslab, Taiwan) at $6,000 \mathrm{rpm}$ for ten minutes. The supernatants were removed and the absorbance values were read using a spectrophotometer (Shimadzu UV-1800, Japan) at a wavelength of $586 \mathrm{~nm}$.

\section{Statistical analysis}

All the data obtained are presented as mean \pm standard deviation (SD) and were analyzed using independent $t$-test using SPSS 21. Differences were considered significant if $p<0.05$.

\section{RESULTS}

The levels of MDA and neutrophil are shown in Table 1. There was no significant difference in MDA levels $(p=0.489)$ between control and treatment groups. The numbers of neutrophils in the control and treatment groups were significantly different $(p=0.003)$. The $\mathrm{HE}$ staining results for the control and treatment group neutrophils are shown in Figure 1.

Table 1: Mean MDA levels and neutrophils in the rats

\begin{tabular}{lcc}
\hline Group & $\begin{array}{c}\text { MDA levels } \\
\text { (mean } \pm \text { SD) }\end{array}$ & $\begin{array}{c}\text { Neutrophil } \\
\text { (mean } \pm \text { SD) }\end{array}$ \\
\hline Control & $4.58 \pm 0.66$ & $30.04 \pm 15.30$ \\
Treatment & $4.30 \pm 0.81$ & $7.76 \pm 2.52^{*}$ \\
\hline${ }^{*}$ Significant different $(p<0.05)$ &
\end{tabular}

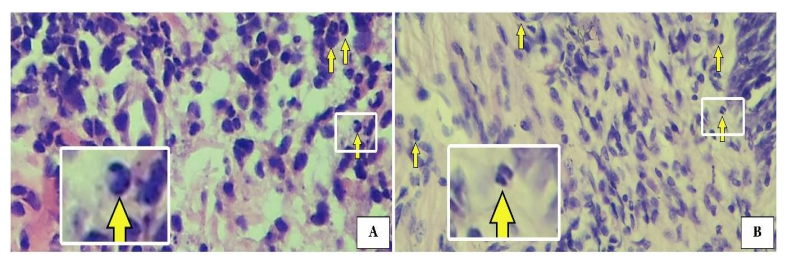

Figure 1: Neutrophil expression (yellow arrow) after HE staining using light microscope 1000x in treatment (A) and control (B) group

\section{DISCUSSION}

Aggressive periodontitis is a periodontal disease which demonstrates a high level of $A$. actinomycetemcomitans. The host response to bacterial infection plays a critical role in periodontal pathogenesis. PMN is a first-line host defense, against the bacteria which utilizes oxygen-dependent and oxygen-independent mechanisms. The oxygen-dependent pathway involves the production of ROS [15], the excessive presence of which may induce periodontal tissue destruction $[15,16]$.

This study used ERW as an alternative therapy for aggressive periodontal disease and was conducted to evaluate its effectiveness in this regard. The subjects were divided into two groups, control and treatment. The control group, serving as a reference standard for comparing MDA and neutrophil levels with those of the treatment group, was treated with distilled water of neutral $\mathrm{pH}$. Distilled water is a clear, colorless, odorless, non-toxic liquid with a molecular weight of $18.0 \mathrm{~g} / \mathrm{mol}$ and $\mathrm{pH}$ of $5-7$. The treatment group was treated using ERW with a pH of 9.8. Previous studies have shown $\mathrm{pH} 9.8$ to be capable of reducing ROS and inflammation in kidney disease [17].

The average level of MDA in the treatment group was lower than that of the control group. However, the results of the analysis confirmed there was no significant difference in the level of MDA between the two groups. This was possibly due to a decrease in the antioxidant activities of ERW. ERW is affected by heat and cannot be consumed immediately since this would lead to the instability of active hydrogen atoms and a decrease in antioxidant activities [18]. Furthermore, the antioxidant capabilities of ERW did not reach their maximum level due to the comparatively short treatment period (three days). Previous results indicated that ERW can reduce the inflammatory process in atopic dermatitis when consumed for 25 days [19]. Furthermore, ERW can decrease ROS activities in blood plasma after being consumed for one month [17].

The level of neutrophil in the treatment group was significantly lower than that of control group. This is related to the anti-inflammatory activities of ERW [17]. For example, ERW with a pH of 9.8 promotes anti-inflammatory activities by lowering the levels of cytokines in mice suffering from atopic dermatitis triggered by Dermatophagoides farinae. Active hydrogen atoms can also reduce pro-inflammatory expressions, including: tumor necrotizing factor-alpha (TNF- $\alpha$ ), interleukin-6 (IL-6), IL-1, IL-10, IL-12, chemokine (C-C motif) ligand 2 (CCL2), intercellular adhesion molecule 1 (ICAM-1), high-mobility group protein 1 (HMGB-1), nuclear factor kappa-light-chainenhancer of activated B cells (NF-kB), and prostaglandin E2 (PGE2). ERW also inhibits cyclooxygenase (Cox-2) expressions by decreasing IL-1 and TNF- $\alpha$. The inhibition of IL-1 and TNF- $\alpha$ synthesis leads to reduced stimulation of cell membrane phospholipids. Consequently, arachidonic acid is not released from the cell membrane phospholipids by phospholipase activation. This condition leads to a reduction in both cox-2 protein synthesis and prostaglandin biosynthesis which, in turn, results in a decreased inflammatory response [20]. The 
inhibition of IL-1 and TNF $\alpha$ synthesis also leads to capillary vasoconstriction and increased capillary permeability. According to Ohta, ERW can also inhibit the release of PGE2 resulting in a decrease in the pain threshold and inflammatory response [10].

\section{CONCLUSION}

The findings of this study indicate that ERW reduces the number of neutrophils without affecting MDA levels in Wistar rats suffering from aggressive periodontitis. These results confirm that ERW was an effective material to manage aggressive periodontitis.

\section{DECLARATIONS}

\section{Acknowledgement}

The Indonesian Ministry of Research, Technology, and Higher Education for a grant for this research in 2015, including the publication of this manuscript.

\section{Conflict of interest}

No conflict of interest is associated with this study.

\section{Contribution of authors}

The authors declare that this work was undertaken by the author(s) named in this article and all liabilities pertaining to claims relating to its contents will be borne by the authors. All the authors made substantial contributions to this study and/or manuscript, approved the final draft of the paper prior to its submission.

\section{REFERENCES}

1. Shewale AH, Gattani DR, Bhatia N, Mahajan R, Saravanan SP. Prevalence of periodontal disease in the general population of india-a: systematic review. J Clin. Diagnostic Res 2016; 10: 4-9. Available at: https://www.ncbi.nlm.nih.gov/pmc/articles/PMC4963791/

2. Health Research and Development Department of Indonesian Health Ministry. Basic Health Research. 2014: 99-102.

3. Melok AW. The difference matrix metalloproteinase-8 level after scalling and after tetracycline application on periodontitis patient. J PDGI 2009; 58: 1-6.

4. Alabandar JM, Tinoco EM. Global epidemiology of periodontal disease in children and young persons. Periodontol 2000 2002; 29: 153-176.

5. Natalina, Masulili SLC, Harsas NA, Subekti I, Auerkari EI. Gingival crevicular fluid levels of resistin and adiponectin in chronic periodontitis with type 2 diabetes mellitus. $J$ Int Dent Med Res 2016; 9: 329-333.

6. Marcuschamer E, Hawley CE, Speckman I, Romero RMD, Molina JN. Lifetime of normal hormonal events and their impact on periodontal health. Perinatol Reprod Hum 2009; 23: 53-64. Available at: http://new.medigraphic.com/cgi-bin/resumen.cgi?IDAR TICULO=21864

7. Kachlany SC. Aggregatibacter actinomycetemcomitans leukotoxin: from threat to therapy. J Dent Res 2010; 89: 561-570. Available at: https://www.ncbi.nlm.nih.gov/ pmc/articles/PMC3144085/

8. Ayala A, Muñoz MF, Argüelles S. Lipid peroxidation: production, metabolism, and signaling mechanisms of malondialdehyde and 4-hydroxy-2-nonenal. oxidative medicine and cellular longevity. Oxidative Medicine and Cellular Longevity 2014; 2014: 1-31. Available at: https://www.ncbi.nlm.nih.gov/pmc/articles/PMC4066722/

9. Dahiya P, Kamal R, Gupta R, Bhardwaj R, Chaudhary K, Kaur $S$. Reactive oxygen species in periodontitis. $J$ Indian Soc Periodontol 2013; 17: 411-6. Available at: https://www.ncbi.n/m.nih.gov/pmc/articles/PMC3800399/

10. Ohta S. Molecular hydrogen is a novel antioxidant to efficiently reduce oxidative stress with potential for the improvement of mitochondrial diseases. Biochimica et Biophysica Acta - General Subjects 2012; 1820: 586594. Available at: http://www.sciencedirect.com/science/ article/pii/S0304416511001103?via\%3Dihub

11. Shirahata S, Li Y, Hamasaki T, Gadek Z, Teruya K, Kabayama S. Redox regulation by reduced water as active hydrogen donors and intracellular ros scavengers for prevention of type 2 diabetes. Cell technology for cell products (ed.Smith E). USA: Springer; 2007: 99-101.

12. Shirahata S, Hamasaki T, Teruya K. Advanced research on the health benefit of reduced water. Trends Food Sci Technol 2012; 23: 124-131. Available at: http://www. sciencedirect.com/science/article/pii/S09242244110024 08

13. Kopko, P. Benefits of alkaline water. USA: Alkaline People Publishing, 2008; pp 3-5.

14. Tan B. Guidelines on the care and use of animals for scientific purposes. National Advisory Committee for Laboratory Animal Research. 2004.

15. Guentsch A, Puklo M, Preshaw PM, Glockmann E, Pfister W, Potempa J, Eick S. Neutrophils in chronic and aggressive periodontitis in interaction with porphyromonas gingivalis and aggregatibacter actinomycetemcomitans. J Periodontal Res 2009; 44: 368-377. Available at: https://www.ncbi.nlm.nih.gov/ pmc/articles/PMC4180098/

16. D'Aiuto F, Nibali L, Parkar M, Patel K, Suvan J, Donos N. Oxidative stress, systemic inflammation, and severe periodontitis. J Dent Res 2010; 89: 1241-1246. Available at: https://www.ncbi.n/m.nih.gov/pmc/articles/ PMC3318025/

17. Huang KC, Yang CC, Hsu SP, Lee KT, Liu HW, Morisawa S, Otsubo K, Chien CT. Electrolyzed-reduced water reduced hemodialysis-induced erythrocyte

Trop J Pharm Res, February 2018; 17(2): 236 
impairment in end-stage renal disease patients. Kidney Int 2006; 70: 391-398. Available at: http://www.science direct.com/science/article/pii/S0085253815519418?via \%3Dihub

18. Henry M, Chambron J. Physico-chemical, biological and therapeutic characteristics of electrolyzed reduced alkaline water (ERAW). Water 2013; 5: 94-115. Available at: http://www.mdpi.com/2073-4441/5/4/2094
19. Ignacio RMC, Joo KB, Lee KJ. Clinical effect and mechanism of alkaline reduced water. Journal of Food and Drug Analysis 2012; 20: 394-397.

20. Kao E, Hsu J, Wang C, Yang S, Lee H. Polyphenols extracted from hibiscus sabdariffa $L$. inhibited lipopolysaccharide-induced inflammation by improving antioxidative conditions and regulating cyclooxygenase2 expression. Biosci Biotechnol Biochem 2009; 73: 385390. Available at: http://www.tandfonline.com/ doi/abs/ $10.1271 / \mathrm{bbb} .80639$ 